\title{
PROBABILISTIC TIME VARIANT ASSESSMENT OF THIN-WALLED STEEL MEMBERS UNDER ATMOSPHERIC CORROSION ATTACK
}

\author{
Lucrezia CASCINI, Francesco PORTIOLI, Raffaele LANDOLFO \\ Department of Structures for Engineering and Architecture, University of Naples "Federico II", \\ 80134 Naples, Italy
}

Received 28 Dec 2011; accepted 28 Aug 2012

\begin{abstract}
Atmospheric corrosion is a relevant problem for steel structures and components exposed in aggressive environment in case of poor and/or unfeasible maintenance and inspection during service life. As for thin-walled members, the corrosion hazard can be exacerbated due to the thin thickness of components and the coupled effect between corrosion and buckling can significantly reduce the structural capacity of such structures. Following these considerations, this paper presents a study on the reliability of a thin-walled steel section subjected to the damage induced by atmospheric corrosion in outdoor environments, combining predictive corrosion models for metals with structural reliability applications. A general procedure for the evaluation of the time variant capacity is proposed and discussed in detail. Finally, an application to a C-lipped cold formed section is presented and a reliability analysis of the deteriorating section is carried out to evaluate the coupled effect of corrosion and buckling, according to the proposed procedure.
\end{abstract}

Keywords: thin-walled steel structures, atmospheric corrosion, reliability, buckling.

Reference to this paper should be made as follows: Cascini, L.; Portioli, F.; Landolfo, R. 2014. Probabilistic time variant assessment of thin-walled steel members under atmospheric corrosion attack, Journal of Civil Engineering and Management 20(3): 404-414. http://dx.doi.org/10.3846/13923730.2013.802709

\section{Introduction}

The durability of thin-walled steel members exposed to aggressive environments is a relevant problem for a great number of structures. Cold-formed framings, trussed roofing structures boldly exposed or partially sheltered in coastal areas, off-shore structures, foundations and all the other components that cannot be inspected or maintained, are typical example of thin walled corrosion prone structures. The durability of such profiles is usually guaranteed by the application of protective coatings, mainly galvanized coatings, and specific thickness is prescribed by international standards (ASTM A1003/A1003 2006) considering the building location, the exposure conditions and other influencing factors.

As a matter of fact, several threats could affect coatings performances such as improper on-site material storage, underestimation of the severity of the environment, or even an inappropriate design of constructional detailing. In such a case, coating failures let the bare steel remain exposed to the atmosphere, sharply increasing the probability of an atmospheric corrosion related failure (Fig. 1).

From the structural point of view, the thickness loss of the cross section leads to a smaller resistant area, producing a decrease of the structural performances in terms of strength, stiffness and ductility. Moreover, in case of cyclic loads, the corrosion phenomenon can produce a significant reduction in the fatigue strength, mainly in zones with high stress concentrations.

Mirambell (2004) observed that corrosion related failures arise mainly because corrosion hazard was not taken into account in the initial design and this leads to a "substantial decrease in structural strength and poses an additional problem in connection with preventative maintenance to counter the effects of the corrosion".

With respect to buildings and civil engineering works, which are the main focus of this paper, the design of steel structures under corrosion attack is usually based on simple criteria and prescriptive rules. Although durability is listed among the basic requirements that each construction shall meet during service life, a review of the design rules and recommendations (Eurocode 2002; Eurocode 3 2005; Probabilistic model code 2000; ISO 12944-1 1998; ISO 14713 2009; EN 1090-1 2009; EN 1090-2 2008), highlights that no mandatory design procedure is defined to quantify the effects of deterioration mechanisms and only conceptual guidance - based on simplified criteria as well as indirect evaluation, and qualitative and common provisions - is provided.

For example, the Eurocode 3 (2005) suggests including "an appropriate corrosion allowance" in the structural dimensioning of steel members that cannot be inspected and maintained during service life. In the same 
way, the Probabilistic model code (Probabilistic model code 2000) recommends to account for deterioration allowance in the dimensioning of structural elements but neither the first nor the second code gives calculation methods.

Other recommendations can be found in ISO 12944-1 (1998) and ISO 14713 (2009) for paint and zinc coatings, EN 1090-1 (2009) for factors affecting execution of coldformed steel (CFS) that need to be specified during design, and EN 1090-2 (2008) for components less than $4 \mathrm{~mm}$ thick.

On the other hand, quantitative assessment of the life time performances of metal structures have been developed in the field of scientific literature (Kaiser, Nowak 1989; Kulicki et al. 1990; Prucz, Kulicki 1998; Sharifi, Paik 2011; van de Lindt, Ahlborn 2005), but most of these studies deal with steel bridge structures and hot rolled profiles.

As for thin-walled steel structures, several studies have been carried out on the durability against corrosion of cold-formed steel structures (Cissel, Quinsey 1942; Larson, Usami 2007; Rourke et al. 2007; Popo-Ola et al. 2000) but in this case, no predictive models have been defined. In particular, a recent AISI project (Steel framing alliance 2004) investigated the potential for corrosion of galvanized cold-formed steel (CFS) framing and fasteners by exposing several test samples, each representing typical residential construction.

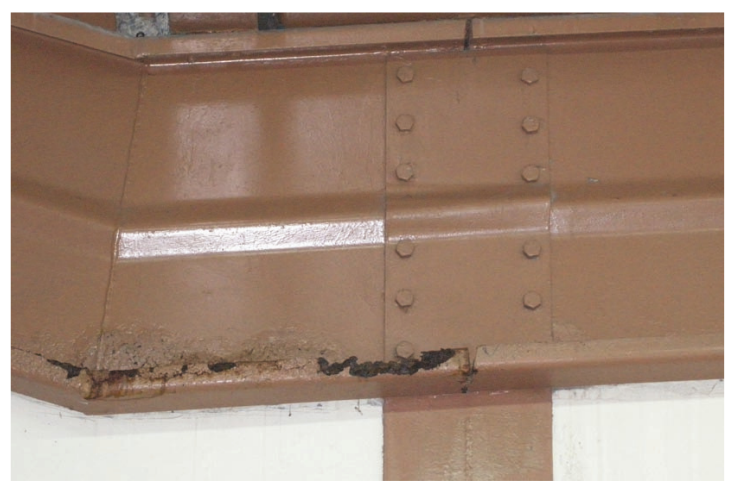

Fig. 1. Corrosion attack on cold-formed beam in an urban atmosphere, sheltered exposure, Naples (Italy)

It was found that CFS members in the partially sheltered exterior exposures (i.e. in the crawl space) showed initiation of corrosion just after 5 months in the coastal areas. This condition proceeded rapidly so that by the $28^{\text {th }}$ month, the exposed floor joists and supporting wall have experienced complete corrosion of the zinc coating and formation of significant rust on the steel section. Also CFS roof framing members and components in vented enclosed exposures were tarnished (absence of the original luster on the zinc galvanizing) with some cuts end corrosion.

As a matter of fact, corrosion of CFS could be a relevant problem in aggressive environment and in particular for a component that cannot be easily inspected during the service life. Indeed, such extreme condition could lead the coating to fail even before the predicted service life, thus fatally impairing the structural capacity of such component.

In addition, the impact of a corrosion threat can be exacerbated in case of CFS structures due to the thin thickness of such profiles. Indeed, as CFS are very sensitive to buckling phenomena, a relative small loss of metal can significantly impair the stability of CFS components.

Following these considerations, this paper presents a study on the reliability of CFS sections subjected to the damage induced by atmospheric corrosion in outdoor environments, combining predictive corrosion models for metals with structural reliability applications.

The main aim of the study is to present a methodological approach for the life-cycle design of CFS that take into account the potential corrosion damage in aggressive environment.

The methodology shall be adopted to address the inspection and maintenance operation according to a quantitative evaluation of a potential attack and/or to define specific corrosion allowance in the design of keycomponent exposed in very-severe corrosion environment.

Although the present study focuses on CFS, and it is mainly based on structural component analysis, it would provide a general framework for the evaluation of durability performances of metal structures against atmospheric corrosion, such as bridges and ship structures. In such a case, other important factors, relevant to the evolution of corrosion damage as a consequence of stress state and cyclic loads, together with the development of systembased safety measures (Frangopol 2011), shall be carefully taken into account.

In this paper, after an introduction on the general approach adopted for the study, a brief literature review on the atmospheric corrosion models, developed in the framework of international research and standards, questions related to the damage pattern of structural components, as well as the formulation of the basic reliability problem, are introduced. An application to a C-lipped cold formed section is presented. The study is carried out according to simplified assumptions, mainly concerning: 1) the adopted corrosion mechanism, which is only uniform corrosion; 2) the analysed loading condition that is the simple case of pure bending; 3 ) the selected random variables. Finally a reliability analysis of the deteriorating section is carried out to evaluate the coupled effect of corrosion and buckling according to the proposed procedure.

\section{General methodology for the evaluation of corrosion effects}

In this section a general approach to evaluate the effect of atmospheric corrosion on the time dependant capacity of a steel section is presented. The method consists of the following steps:

I. Corrosion susceptibility analysis: in this first step a qualitative and/or quantitative assessment of the existing or potential corrosion attack for a given metal in a given environment is carried out. This step includes the identi- 
fication of the main forms and mechanism of corrosion, the evaluation of the severity of the environment and the establishment of a deterioration model at material level.

II. Corrosion damage analysis: in this second step, the assessment of the damage induced by the identified corrosion mechanism(s) for a given structure and/or structural component is carried out. A set of time points $t_{i}$ is defined, covering the entire life cycle interval $\Delta T$, and corresponding corroded geometries are identified.

III. Corrosion reliability analysis: in this step the probability of a corrosion related failure is assessed. Relevant failure modes are identified and corresponding reduced capacities are evaluated for each selected point of time. A structural reliability analysis is carried out, by means of the definition of reliability indexes $\beta$ as a function of time.

\subsection{Corrosion susceptibility analysis}

Corrosion is the deterioration of a material, usually a metal, that results from a reaction with its environment (NACE 2002), causing the degradation of both.

In order to assess the existing or potential corrosion attack for a given metal in a given environment, three main items shall be addresses: 1) the form of corrosion; 2) the mechanics of corrosion; 3) the basic variables involved.

As for corrosion forms, only atmospheric corrosion, which occurs in outdoor and indoor natural environments as a consequence of wet and dry cycles induced by rainfall and condensation, is considered in this study.

The basic variables affecting the corrosion rate of a given metal in a given corrosive environment are function of material related factors (such as the effective electrode potential of a metal in a solution, the composition of the metal, the chemical and physical homogeneity of the surface, etc.), and factors related to the atmosphere. As key environmental factors, Vernon (1935) identified the time of wetness (that is the average period of time during which the electrolyte is on the corroding surface (Roberdge 2000)) also defined as the number of hours, during which the relative humidity is greater than $80 \%$ and the average temperature $\mathrm{T}>0^{\circ}$ (UNI EN 12500 2002), and the concentration of contaminants, such as sulphur dioxide and chlorides.

In order to assess the severity of an outdoor environment a qualitative and/or a quantitative assessment can be carried out (UNI EN 12500 2002; ISO 9224 1992). In any case, climatic and meteorological data for the project site are required. According to the ISO classification system (ISO 9223 1992), five "corrosivity classes" (C1-C5) are defined and corrosivity charts are provided, reporting guiding values of TOW, sulphur dioxide concentration and the chloride deposition rate. The corrosivity categories defined in the standard are really suitable for engineering purpose because the corrosion property of the atmosphere is expressed by means of influence parameters in a quantitative approach.

As for prediction models, in the following study only models for uniform corrosion, that is a kind of general corrosion that proceeds at the same rate onto the metal surface, will be considered.

A corrosion model suitable for structural engineering application should provide information concerning the thickness loss by a metal over time as a function of the mechanics of the phenomena and the influencing parameters (i.e. the specific material under investigation, the exposure atmosphere...). The model should also provide the statistical variation of variables.

A literature review (Cascini et al. 2008; Landolfo et al. 2010) revealed that models for uniform corrosion provide the corrosion rate as the mass loss per unit area per unit time, or as the rate of penetration, by means of the thickness loss. Corrosion models usually describe the corrosion depth as a function of time in the form of a power model:

$$
d(t)=A t^{B},
$$

where: $d(t)$ is the corrosion depth $\left[\mu \mathrm{m}, \mathrm{g} / \mathrm{m}^{2}\right] ; t$ is the exposure time [years]; $A$ is the corrosion rate in the first year of exposure; $B$ is the corrosion rate long-term decrease.

Because of the formation of corrosion products on the metal surface, the initial corrosion rate usually decreases on long term period. If $B$ is smaller than 0.5 , the corrosion products show protective, passivating characteristics, otherwise $B$ is greater than 0.5 . Some simplified models have been proposed, which take into account the environmental effects influencing the corrosion rate by means of constant values of coefficients $A$ and $B$. Such models express the thickness loss only as a function of time and are usually calibrated on data obtained from short and long term field test exposure. As a consequence, if they are used for environments which differ from the one where the model has been calibrated, the predicted value of the corrosion rate is often inaccurate. A first attempt to develop general models has been provided by International Standard ISO 9224.

The International Standard ISO 9224 (1992) specifies the long term corrosion rates for standard structural materials in the five corrosivity classes $\mathrm{C} 1-\mathrm{C} 5$. According to the Standard, the average corrosion rate of each material follows a bi-linear law. During the first 10 years (i.e. for if $t<10$ years), the corrosion depth is given by the equation:

$$
d_{1}(t)=r_{a v} \cdot t,
$$

where: $d_{1}(t)$ is the corrosion depth after the first 10 years of exposure (micrometers); $r_{a v}$ is the average corrosion rate (micrometers per year); $t$ is the time at which the exposure ends.

After 10 years of exposure (for $t \geq 10$ years) the corrosion rate is assumed to be constant with time and the thickness loss is given by the equation:

$$
d(t)=r_{a v} \cdot 10+r_{\text {lin }}(t-10),
$$

where: $d(t)$ is the corrosion depth for the considered time interval (micrometers); $r_{l i n}$ is the steady state corrosion rate (micrometers per year); $t$ is the time in the linear region of the curve of uniform corrosion as function of time. 


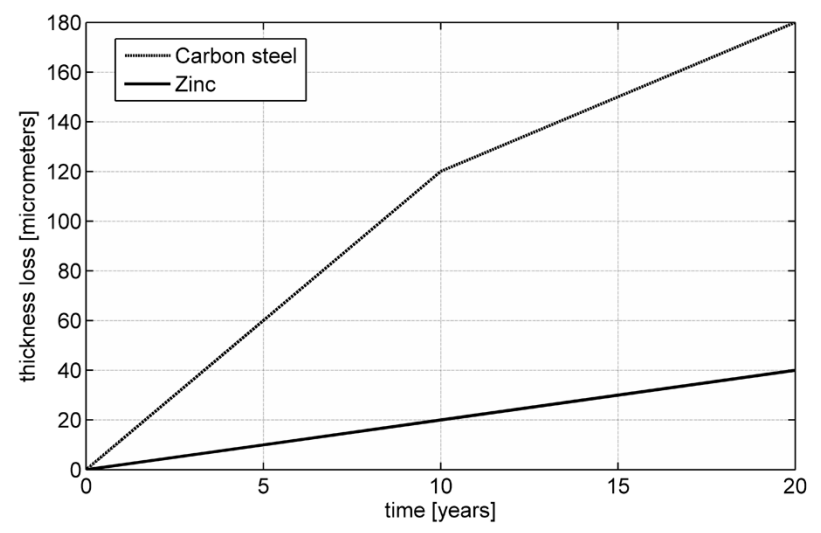

Fig. 2. A comparison between the corrosion rate of carbon steel and zinc in a medium corrosivity class C3 according to ISO 9224 (1992)

Among others, the standard provides the guiding values of both $r_{a v}$ and $r_{l i n}$ for carbon steel and zinc (Fig. 2).

Some adjustment to these corrosion laws have been reported in Albrecht and Hall (2003). A new bi-linear model has been proposed, which accounts for a modified corrosion rate during the first year of exposure and a steady state during the subsequent years.

Recently, different models have been developed with the aim to generalize the corrosion loss over time for different environments, reporting the climate and pollutants variables as independent factors. Klinesmith et al. (2007) developed a model for the atmospheric corrosion of carbon steel, zinc, copper and aluminium, taking into account the effects of the time-of-wetness, the sulphur dioxide concentration and the chloride deposition rate. Further details concerning these models can be found in (Klinesmith et al. 2007).

Although several models have been developed with the aim to predict the corrosion rate of a given metal in a give environment, so far it is still possible to observe a large scatter in the prediction of corrosion rate, and several uncertainties arise for the correlation of material corrosion rates with environmental parameters. In line with that, Knotkova et al. (2010) are reviewing the corrosion models and rates provided by the ISO standards aiming to provide new "basis for the classification of corrosivity according to the $\mathrm{C} 1$ to $\mathrm{C} 5$ categories". So far, a new series of these standards is under development having the goal to provide "new procedure for assessing guiding values for corrosivity categories after longer exposure times" as well as "standardized measurement methods were extended and adjusted".

\subsection{Corrosion damage analysis}

The description of the corrosion damage at component level should include the location along the structure, the potential area affected by corrosion, the velocity of the attack, as well as the probability of damage occurrence within a given period of time.

Most of the corrosion models presented in the previous section have been calibrated on the basis of field test exposure of flat or helix small samples of different metals. As a matter of fact, the corrosion rate estimated from measures performed on small samples could be very different from the corrosion rate of a structural member as a whole. That is mainly because, at component level, the deterioration of a metal structure is strongly influenced by both the local exposure condition and the steel construction details.

As for steel structures exposed to outdoor environment, it has been noted that uniform corrosion is one of the most form of degradation affecting the structural component.

At component level corrosion is most likely to occur in zones where moisture and dirt shall be entrapped, as in cavity, or where the water drainage is not efficient, in case of open crevices. In order to model the damage pattern at component level, consideration concerning the specific structural component under investigation shall be made, and the damage pattern due to corrosion shall be defined according to visual inspection, past experience and observation of similar structures.

Czarnecki and Nowak (2008) found that, in case of steel bridges, "field survey results indicate that corrosion is most likely to occur along the top surface of the bottom flange, due to traffic spray accumulation, and over the entire web near the support, due to deck leakage". Sarveswaran et al. (1998) developed a cross sectional damage pattern of four beams recovered from a chemical plant founding that corrosion is most likely to appear in the lower flange of the IPE beam and up to $1 / 4$ of the web height.

In addition to the local exposure and the steel construction details, other important factors, related to the loading condition and the stress states of components, shall be considered for the proper definition of damage models.

As an example, the combined effect of static tensile stress and corrosive environments may lead to stress corrosion cracking - a form of corrosion that affect, in particular, metal characterized by low fracture resistance and involves the initiation of cracks and their propagation in metal, which may occur even in very short time. Besides, also the effect of cycling loading may be exacerbated in a corrosive environment. Indeed, in case of fatigue corrosion, the fatigue-crack-growth rate is enhanced by corrosion and a reduction in the fatigue life is generally observed (Kaiser, Nowak 1989; Fisher et al. 1998).

The effect of loading and unloading process combined with corrosion was recently investigated by Melchers and Paik (2010). The authors found that the corrosion rate of steel plates exposed to marine environment may increase of above $10-15 \%$, respect to the corrosion loss curve reported in the literature, when combined with flexure, thus fatally impairing the performance of structural component.

As a matter of fact, the problem of modelling the damage due to corrosion involves several questions.

In the following application, considering that specific studies on CFS are missing, a simplified corrosion damage model will be formulated on the basis of corrosion models developed for steel structures. 


\subsection{Corrosion reliability analysis}

The problem of assessing and evaluating the lifetime performance of deteriorating structures arise as a new challenge for structural engineers. Several studies have been developed in the field of reinforced concrete structures (Biondini et al. 2006; Biondini, Frangopol 2008, 2009), considering both the damage induced in aggressive environments and the corresponding effect on structural reliability.

As for steel structures, few studies (i.e. Cascini et al. 2012; Ivanov 2009; Kaiser, Nowak 1989; Kulicki et al. 1990; Landolfo et al. 2011; Prucz, Kulicki 1998; Reid 2009; Sharifi, Paik 2011; van de Lindt, Ahlborn 2005) are devoted to the evaluation of life time performance of metal structures according to a reliability based approach.

In order to evaluate the effect of the deterioration induced by atmospheric corrosion, a deterministic approach is seldom feasible, due to the inherent uncertainties related to the variables involved in the problem. Indeed a probability based design approach is a more coherent way to solve the problem. In such a case, the basic variables (action and environmental influences, properties of materials, geometrical parameters, etc.) are identified and modelled as random variables or stochastic processes. Each basic variable is thus defined by a number of parameters such as mean value, standard deviation, etc. (Probabilistic model code 2000; ISO 2394 1998), which describe the proper probability distribution.

The first step in applying probabilistic methods is to decide on what constitutes unsatisfactory performance. Mathematically, this is achieved by defining a performance function $g(\boldsymbol{X})$ where $\boldsymbol{X}$ is a vector of $n$-basic random variables $\left(X_{1} \ldots X_{n}\right)$, including resistance parameters, load effects, geometry parameters and modelling uncertainties. The structure is considered to survive if $g \geq 0$ (satisfactory performance), otherwise to fail ( $g<0$ defines unsatisfactory performance or failure). The attainment of a limit state is represented by the following equation (the so-called limit state equation):

$$
g(X)=g\left(X_{1}, \ldots ., X_{n}\right)=0 .
$$

A measure of the structural reliability is obtained through the performance function as the probability of failure according to Eqn (5):

$$
P_{\text {fail }}=P\left\{g\left(X_{i}\right) \leq 0\right\} \text {. }
$$

In the case of time-dependent variables, the minimum of $g$ with respect to time should be considered.

The failure probability, $P_{\text {fail }}$, shall be also evaluated by means of a reliability index, $\beta$, that is defined as:

$$
\beta=-\Phi^{-1}\left(P_{\text {fail }}\right) \text {, }
$$

where $\Phi$ is the inverse standardized normal distribution.

In order to overcome the difficulties related with the numerical solution of Eqns (5) and (6), in case of a large number of variables, unavailable information and/or lack of data on the probability distribution functions of the basic variables, approximated methods shall be used (Melchers 1999).

As for practical life cycle reliability assessment, several methods have been developed in the framework of scientific literature. In this paper an application of methods developed by Frangopol et al. (Frangopol 2011; Saydam, Frangopol 2011; Okasha, Frangopol 2010) will be adapted to the reliability evaluation of the cold-formed structures under progressive corrosion damage. The proposed method consists in the following steps:

1. Definition of the life-cycle;

2. Definition of the limit state(s) of interest;

3. Benchmark deterministic structural analysis;

4. Probabilistic life-cycle reliability analysis.

In the first step, the period of time to be considered in the analysis shall be identified. That may include the entire life-cycle, which is the period of time from the construction stage to the end of life of the construction work, or just a part of it. The reference time period is modelled as a discrete set of relevant time points $t=\left[t_{0} \ldots \ldots t_{1}\right]$, each corresponding to a significant event of the life cycle (i.e. a planned maintenance operation, an insitu inspection, the attainment of a given deterioration, etc.). For each time point $t^{*}$, the damage scenarios $D_{i}=D_{i}\left(t^{*}\right)$ shall be defined by means of deterioration of materials and damage of components.

As for the definition of the limit state(s) of interest, several references can be found in the international standard and codes considering both the structure under investigation and the specific performance to be achieved (i.e. ISO 23941998 for building and other civil engineering works; ISO 18072-1 for ship structures, etc). Generally speaking ultimate limit states, serviceability limit states, fatigue limit states and accidental limit states can be considered. With respect to durability performance over time, specific reference will be made to ISO 13823 (2008) on the "General principles on the design of structures for durability". According to ISO 13823 (2008), the performance objective shall be defined by means of durability limit states. Those refer to the attainment of a specific basic requirement taking into account the degradation mechanism induced by the environment. According to the standard, three durability limit states are defined, namely: ultimate durability limit state $(U L S-D)$, if the material deterioration results in a capacity loss that impairs the safety of the people and/or of the structure; serviceability durability limit state $(S L S-D)$, when local damage and/or relative displacement affect the functionality and/or the appearance of the construction; initiation limit state (ILS) corresponding to the initiation of significant deterioration. In particular, the ultimate durability limit state shall be defined as the condition beyond which the capacity of the component or structure, $R(t)$, becomes equal to - or less then- the demand, $E(t)$, acting on it.

In the third step, the benchmark deterministic structural analysis is performed. At this stage, the numerical model of a structure is generated in the deterministic domain, with the mean (or nominal) value of the basic 
variables. Then, for each time point $t^{*}$ of the life cycle, the structural analysis is repeated, and a sub-set of the basic variables, to be modelled as random, is identified. Those can be material properties, geometries, deterioration rates, damage pattern, action effect, etc. The probabilistic domain is formulated assuming a proper probability distribution for each basic variable $X_{i}$. In this way, for each time point $t^{*}$ of the life cycle $t$, the vector of random input $X$ is defined:

$$
X\left(t^{*}\right)=X\left[X_{1}\left(t^{*}\right), \ldots \ldots X_{n}\left(t^{*}\right)\right] .
$$

Once the input is defined, a random sampling is performed with the Latin hypercube sampling method one of the most efficient importance sampling method usually adopted for structural reliability analysis (Olsson et al. 2003). For each time point $t^{*}$ of the life cycle $t$, the perturbation technique leads to a set of $m$ combinations of the random variables:

$$
\begin{gathered}
\boldsymbol{X}^{(i)}=X\left[X_{1}{ }^{(i)}, X_{2}{ }^{(i)} \ldots \ldots X_{n}{ }^{(i)}\right] \\
i=1 \ldots \ldots m \quad \forall t^{*} \in t
\end{gathered}
$$

The structural analysis is repeated $m$-times, at the pre-determined values of the random variable. The probability distribution of the structural response, $R(\boldsymbol{X})$, is then approximated using statistical methods on the results of the repeated structural analysis. The capacity of the structure, and the probability distribution of the output, are obtained by fitting the outcomes of the numerical model as a function of the input random variables.

$$
\begin{aligned}
& \boldsymbol{R}(\boldsymbol{X})=f\left[R\left(X^{(i)}\right)\right] \\
& i=1 \ldots . . m \quad \forall t^{*} \in t
\end{aligned}
$$

Once the statistical distribution of the structural capacity has been obtained, a limit state equation is formulated (Eqn (10)), introducing the statistical distribution of the load-effect $E$. The point in time reliability index $\beta$ is evaluated through approximated methods and/or according to Eqn (11):

$$
\begin{gathered}
g\left(t^{*}\right)=R\left(t^{*}\right)-E\left(t^{*}\right) \leq 0 \quad \forall t^{*} \in t ; \\
\beta\left(t^{*}\right)=\frac{\mu_{R}\left(t^{*}\right)-\mu_{E}\left(t^{*}\right)}{\sqrt{\sigma_{R}^{2}\left(t^{*}\right)+\sigma_{E}^{2}\left(t^{*}\right)}} \quad \forall t^{*} \in t .
\end{gathered}
$$

In the following sections, an application of the proposed approach to the probabilistic time variant assessment of cold formed members in bending, under corrosion attack, is presented.

\section{Application: structural analysis of corroding cold-formed C-lipped beams}

As an example of application of the proposed procedure, in this section, the ultimate flexural strength capacity of a galvanized cold-formed C-lipped section is evaluated as a function of the deterioration induced by atmospheric corrosion. The application is carried out in order to assess the coupled effect of corrosion and buckling, with the aim to quantify the effect of corrosion on the structural capac- ity over time. As for the corrosion susceptibility analysis and corrosion damage analysis, literature data will be adopted. The corrosion reliability analysis is carried out according to the methodology presented in Section 1.

The main input of the analysis are: the cross section dimensions in the as-built configuration, the corroded geometries for a discrete set of percentage of thickness lost, and the material properties.

The dimensions of the cross-section and the material properties in the as-built configuration are summarised in Table 1:

Table 1. Cross section dimensions in the as-built configuration and material properties

\begin{tabular}{lcr}
\hline \multicolumn{1}{c}{ Nomenclature } & Symbol & Dimension \\
\hline Total height & $\mathrm{h}$ & $400 \mathrm{~mm}$ \\
Total width of upper flange & $\mathrm{b}_{2}$ & $150 \mathrm{~mm}$ \\
Total width of bottom flange & $\mathrm{b}_{1}$ & $150 \mathrm{~mm}$ \\
Total width of upper edge fold & $\mathrm{c}_{2}$ & $50 \mathrm{~mm}$ \\
Total width of bottom edge fold & $\mathrm{c}_{2}$ & $50 \mathrm{~mm}$ \\
Steel core thickness & $\mathrm{s}_{0}$ & $4 \mathrm{~mm}$ \\
Basic yield strength & $\mathrm{f}_{\mathrm{yd}}$ & $235 \mathrm{~N} / \mathrm{mm}^{2}$ \\
Modulus of elasticity & $\mathrm{E}$ & $210000 \mathrm{~N} / \mathrm{mm}^{2}$ \\
\hline
\end{tabular}

The damage at cross section level is represented by a dimensionless parameter $\xi(t)$ that is the percentage of thickness lost by the metal with respect to the initial thickness $s_{0}$.

$$
\xi(t)=\frac{s_{0}-s(t)}{s_{0}} .
$$

It is assumed that the zinc coating is not in service. Corrosion refers to the bare structural metal directly exposed to the atmosphere, and the progressive thickness lost ranges from $0.1 \%$ up to $40 \%$ of the initial thickness. As for cross section damage, it is assumed that the uniform corrosion is distributed along the bottom flange up to $1 / 4$ of the web height (Fig. 3), according to Sarveswaran's model (Sarveswaran et al. 1998).

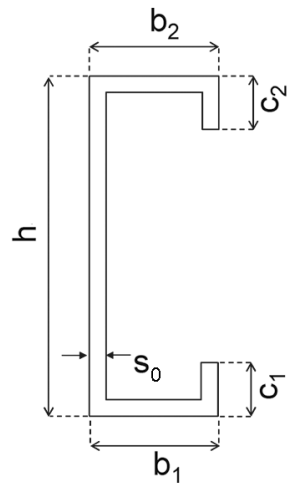

a)

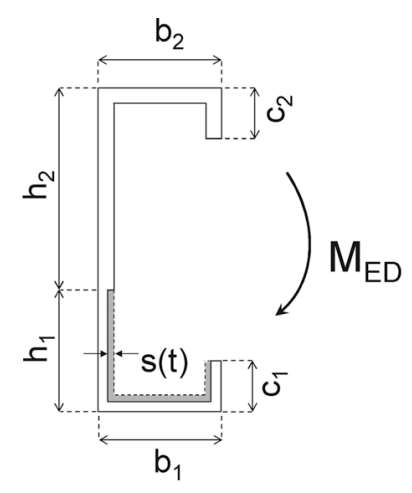

b)
Fig. 3. The investigated C-lipped cross section: a) the as-built configuration; b) the assumed damage model at cross section level 


\subsection{Benchmark deterministic analysis}

The ultimate flexural capacity of the beam is evaluated in the as-built configuration and for different damage stages. As for computation methods, the Direct Strength Method is applied (Schafer 2006). This methods leads to the definition of the elastic buckling load for global, local and distortional buckling. This information along with the load that causes first yield is then employed in a series of simple equations to "directly" provide the strength prediction (Schafer 2006).

An elastic buckling analysis has been performed for a set of discrete time points, each corresponding to an increase of the percentage thickness lost due to corrosion. The buckling analysis were carried out by the finite strip method [CUFSM VERSION 3.12] (Schafer, Adani 2006; $\mathrm{Li}$, Schafer 2010). The cross-section geometry is modelled with ten nodes and nine elements. At each step of the analysis, the thickness of the corroding elements has been reduced according to the adopted damage model, being the other elements undamaged.

For each step of the analysis, load factors corresponding to the relevant buckling modes have been obtained. Then, the Direct Strength expressions have been used to provide the strength in local buckling $\left(M_{n l}\right)$ and distorsional buckling $\left(M_{n d}\right)$.

It is assumed that the ultimate flexural strength of the cold-formed beam $\left(M_{r d}\right)$, for each instant of time $t$, is the minimum moment among the moment at first yield, $M_{y}$, the nominal flexural strength for local buckling $M_{n l}$ and the nominal flexural strength, for distortional buck$\operatorname{ling} M_{n d}$.

$$
M_{r d}(\xi)=\min \left[M_{y}(\xi), M_{n l}(\xi), M_{n d}(\xi)\right] .
$$

As for global buckling, the beam is assumed to be fully laterally braced, thus the global buckling strength $M_{n e}$ is simply the moment at first yield, $M_{y}$.

As for local and distortional buckling strength, the AISI equations for the design of cold-formed steel beams, using the direct strength method, have been used (North American Specification 2004).

In Figure 4 the moment at first yield, $M_{y}$, the nominal flexural strength for local buckling $M_{n l}$ and the nominal flexural strength, for distortional buckling $M_{n d}$ are

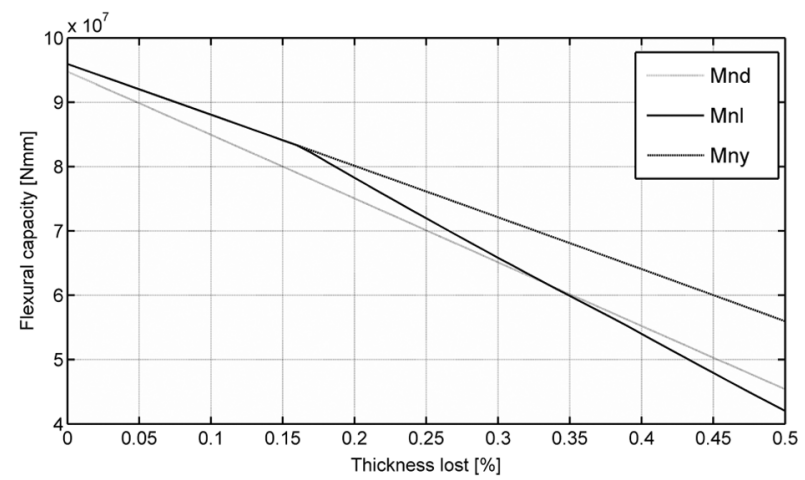

Fig. 4. The evolution of the moment at first yield, $M_{y}$, the nominal flexural strength for local buckling $M_{n l}$ and the nominal flexural strength, for distortional buckling $M_{n d}$ as a function of the dimensionless deterioration $\xi(t)$

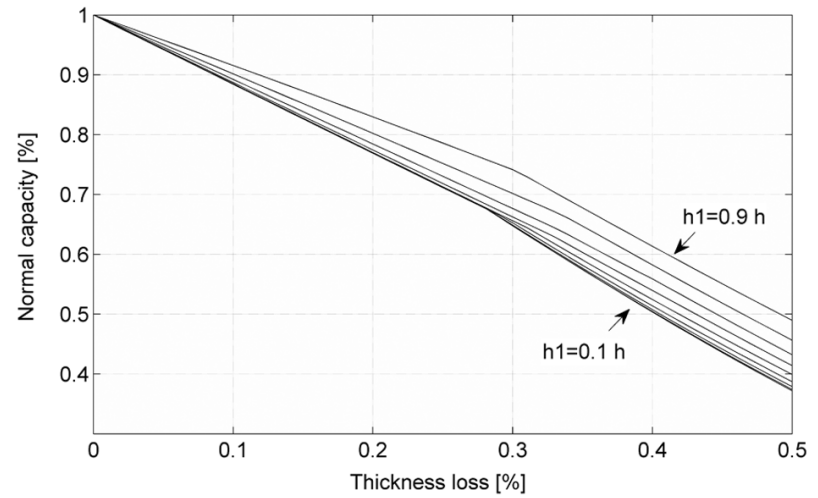

Fig. 5. A sensitivity analysis on the corrosion height $h_{1}$

plotted as a function of the dimensionless deterioration $\xi(t)$. It is interesting to note that the buckling phenomena exacerbate the effect of corrosion on the capacity over time above the $50 \%$ of initial capacity. Besides the increasing damage causes an inversion of the predominant buckling mode from distortional to local.

\subsection{Reliability analysis: evaluation of failure probability and reliability index}

In this section, the structural analysis have been repeated following the life-cycle reliability methods presented in Section 3.

In order to evaluate the time-dependant reliability of the analysed cross section overt time, the limit state equation has been formulated in terms of random variables:

$$
g\left(\xi, f_{y}\right)=M_{R D}\left(\xi, f_{y}\right)-M_{E D}=0 .
$$

The time variant reliability index $\beta(t)$ is evaluated over a life time of 50 years by assuming the steel strength $f_{y}$ and the corrosion thickness loss as random variables.

The yield strength of the steel $f_{y}$ is modelled by a time-invariant normal distribution. As for deterioration modelling, the life-cycle interval $\Delta t$ has been divided in a set of six time points $t_{i}$, where each step corresponds to a time length of 10 years. The lower bound of the time step is assumed to be the initiation time of degradation that is the instant of time corresponding to the zinc coating failure; the upper bound is the end of life cycle, corresponding to a service life of 50 years. It is assumed that in a corrosivity class $\mathrm{C} 3$ the corrosion rate of the bare materials is represented by the upper bound of corrosion rates provided by the standard for carbon steel. Due to the uncertainties related to corrosion models, the corrosion rate of steel is modelled as a random variable, normal distributed, with mean value given by the ISO corrosion model the coefficient of variation being constant. The dimensionless the percentage of thickness loss $\xi(t)$ is now related to the corrosion rate of the carbon steel according to Eqn (15):

$$
\xi(t)=d(t) / s_{0} .
$$

The dimensionless percentage of thickness loss is thus modelled as a random variable (Figs 6-7), normal distributed, with mean and standard deviation given in Table 2. 
Table 2. Random variables used in the reliability analysis of cold-formed C-lipped section

\begin{tabular}{|c|c|c|c|c|c|c|}
\hline :气 & $\stackrel{\Xi}{\Xi}$ & 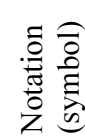 & 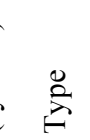 & $\sum_{\Sigma}^{\mathbb{E}}$ & 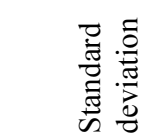 & 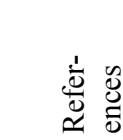 \\
\hline 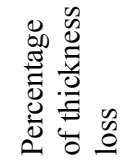 & $\%$ & $\xi(\mathrm{t})$ & $\mathrm{N}$ & $\mu$ & $\sigma=0.15 * \mu$ & $\begin{array}{l}\text { Sarves } \\
\text { waran, } \\
1998\end{array}$ \\
\hline 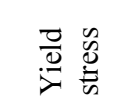 & $\mathrm{N} / \mathrm{mm}^{2}$ & $f_{y}$ & $\mathrm{~N}$ & 265.00 & $0 \quad 18.55$ & $\begin{array}{l}\text { JCSS, } \\
2000\end{array}$ \\
\hline \multicolumn{7}{|c|}{$\begin{array}{l}\text { Table 3. The mean values and standard deviations of the } \\
\text { assumed deterioration model }\end{array}$} \\
\hline \multirow{2}{*}{$\begin{array}{c}t \\
{[\text { years] }}\end{array}$} & \multicolumn{3}{|c|}{$d(t) N[\mathrm{~mm}]$} & & \multicolumn{2}{|c|}{$\xi(t) N[\%]$} \\
\hline & & $\mu$ & $\sigma$ & & $\mu$ & $\sigma$ \\
\hline 0.1 & 0.0 & & 0.0015 & & $0.08 \%$ & 0.0004 \\
\hline 10 & 0.31 & & 0.1500 & & $7.50 \%$ & 0.0375 \\
\hline 20 & 0.5 & & 0.2500 & & $12.50 \%$ & 0.0625 \\
\hline 30 & 0.7 & & 0.3500 & & $17.50 \%$ & 0.0875 \\
\hline 40 & 0.9 & & 0.4500 & & $22.50 \%$ & 0.1125 \\
\hline 50 & 1.10 & & 0.5500 & & $27.50 \%$ & 0.1375 \\
\hline
\end{tabular}

$\mathrm{Hp}$ : it is assumed that $\operatorname{COV}[\mathrm{d}(\mathrm{t})]=\cos \mathrm{t}=0.15$

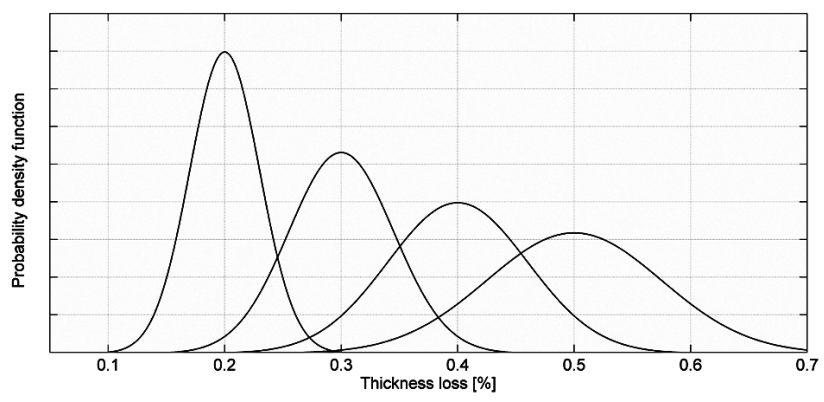

Fig. 6. The probability density function of the dimensionless corrosion damage $\xi(t)$ as a function of time $t$

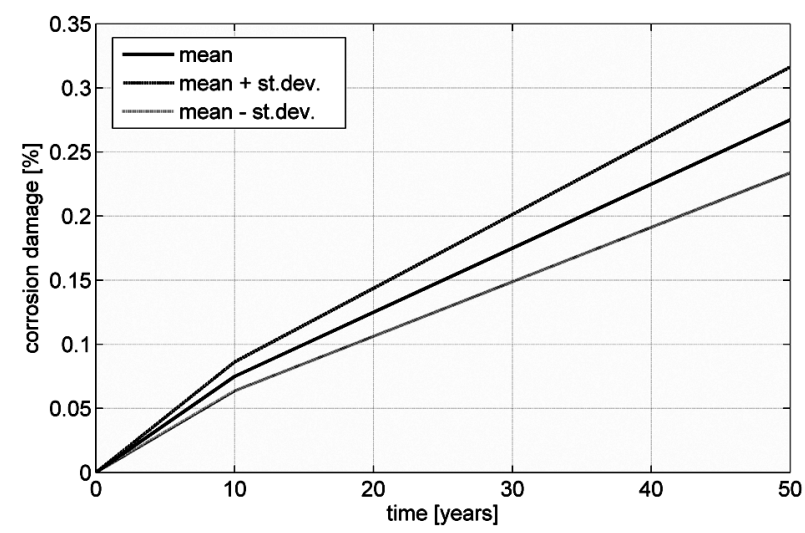

Fig. 7. The dimensionless corrosion damage $\xi(t)$ as a function of time $t$
The ultimate flexural strength of the cold-formed beam $M_{r d}$ is computed according to Eqn (16):

$$
M_{R D}(t)=f\left[\xi(t), f_{y}\right] .
$$

In order to find a proper statistical distribution for the output, the finite strip element analysis have been repeated in a reduced space of random variables by using a Latin hypercube sampling of the basic variables for each time set of the life-cycle $t$ (Fig. 8). Then for each identified damage scenario the output distribution has been identified (Fig. 9).

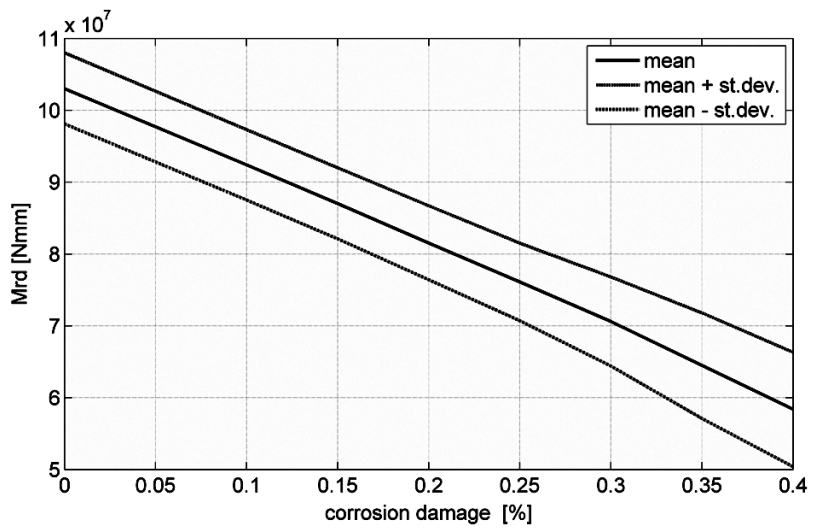

Fig. 8. The time dependant ultimate flexural strength of the beam as a function of the corrosion damage

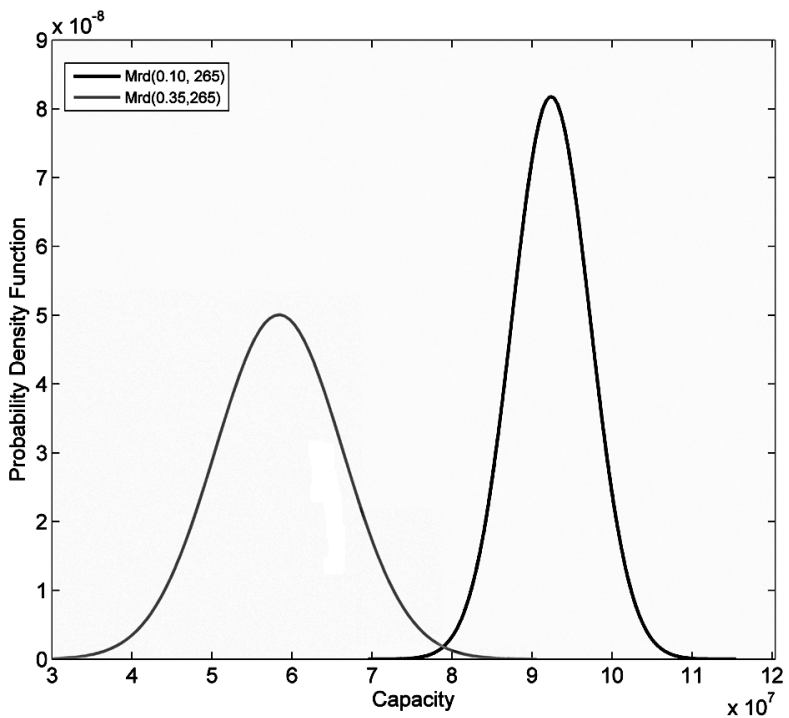

Fig. 9. Two plots of the time-dependant PDF of the capacity for a mean steel strength $f_{y}=235 \mathrm{~N} / \mathrm{mm}^{2}$ and a mean thickness loss of $10 \%$ (grey line) and $35 \%$ (black line)

The simulations reveal a distribution for $M_{r d}$ that look normal in shape with the parameters given in Table 4 .

Once the cross section capacity has been established it has been compared with a time invariant acting bending moment defined as to meet, at the beginning of service life $(t=0)$, the basic reliability index defined in the Eurocode for a 50 years design working life $\left(\beta_{\text {target }}=4.7\right)$. The acting moment is assumed to be normally distributed with a mean value $\mu_{\text {Med }}=6.83 \mathrm{E}+07$ and a standard deviation $\sigma_{\text {Med }}=5.21 \mathrm{E}+06$. 
Tables 4. The statistical parameters of the ultimate flexural strength of the cold-formed beam

\begin{tabular}{c|c|c|c}
\hline \multicolumn{2}{c|}{$\xi(t)[\%]$} & \multicolumn{2}{c}{$M_{r d}[\mathrm{Nmm}]$} \\
\hline$\mu$ & $\sigma$ & $\mu$ & $\sigma$ \\
\hline 0.000 & 0.000 & $1.03 \mathrm{E}+08$ & $5.21 \mathrm{E}+06$ \\
0.100 & 0.015 & $9.24 \mathrm{E}+07$ & $4.88 \mathrm{E}+06$ \\
0.150 & 0.023 & $8.70 \mathrm{E}+07$ & $4.95 \mathrm{E}+06$ \\
0.200 & 0.030 & $8.15 \mathrm{E}+07$ & $5.15 \mathrm{E}+06$ \\
0.250 & 0.038 & $7.61 \mathrm{E}+07$ & $5.42 \mathrm{E}+06$ \\
0.300 & 0.045 & $7.06 \mathrm{E}+07$ & $6.22 \mathrm{E}+06$ \\
0.350 & 0.053 & $6.45 \mathrm{E}+07$ & $7.38 \mathrm{E}+06$ \\
0.400 & 0.060 & $5.84 \mathrm{E}+07$ & $7.97 \mathrm{E}+06$ \\
\hline
\end{tabular}

The reliability index $\beta(t)$ is evaluated according to Eqn (11) and then compared with the target reliability index (Fig. 10).

Target reliability indexes $\beta_{\text {target }}$ have been selected assuming the same values that are usually adopted in the ordinary mechanical design the structural codes (Eurocode 2002; Probabilistic model code 2000). Following the recommendations given in (Eurocode 2002), for reference periods not reported in the codes, the target reliability index has been obtained rearranging Eqn (17):

$$
\Phi\left(\beta_{n}\right)=\left[\Phi\left(\beta_{1}\right)\right]^{n},
$$

where: $\Phi($.$) is the standard normal function of the relia-$ bility index $\beta ; \beta_{1}$ is the reliability index for a reference period of 1 year; and $\beta_{n}$ is the reliability index for a reference period of $n$ years.

Tables 5. The target and computed reliability indexes as a function of time

\begin{tabular}{cccc}
\hline$t$ & $\xi(t)$ & $\beta_{\text {target }}$ & $\beta$ \\
\hline [years] & $\%$ & & \\
0 & 0.000 & 4.7 & 4.70 \\
10 & 0.075 & 4.21 & 3.76 \\
20 & 0.125 & 4.05 & 3.00 \\
30 & 0.175 & 3.95 & 2.20 \\
40 & 0.225 & 3.88 & 1.40 \\
50 & 0.275 & 3.83 & 0.60 \\
\hline
\end{tabular}

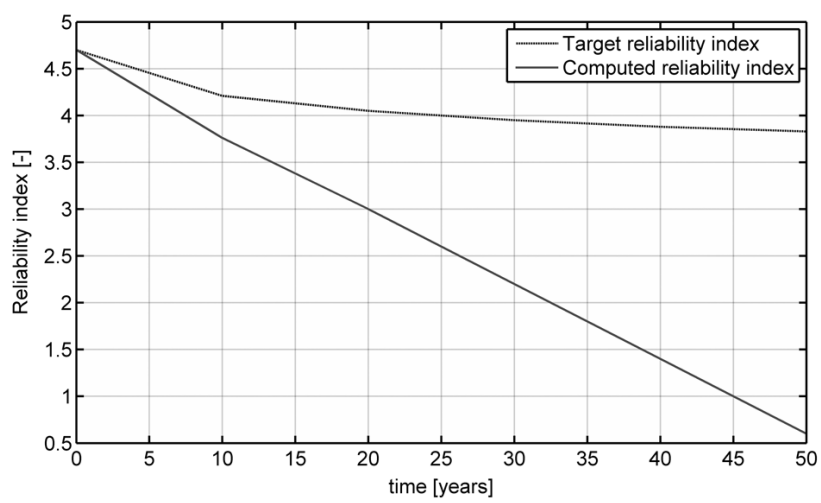

Fig. 10. The reliability indexes plotted versus time. A comparison between the target reliability index (dashed line) and calculated reliability index (solid line)

\section{Conclusion}

In this paper a general procedure for the evaluation of the time variant capacity of cold-formed steel members in bending under atmospheric corrosion attack has been presented. The methodology is based on a simplified probabilistic approach in order to take into account the uncertainties related with deterioration process. The method has been presented and discussed in detail and an application of a time dependant reliability analysis to a corroding cold-formed section has been carried out. The beam under investigation is a C-lipped beam. The corrosion model for the structural material as well as the damage pattern at cross section level have been selected according to the models presented in the scientific literature. Different corroded geometries have been defined for a time set of six time points, ranging from 0 to 50 years. The evaluation of the ultimate flexural strength of the beam over time has been assessed by means of an elastic buckling analysis performed for each step of the time set. In order to consider the uncertainties related to the basic variables involved in the assessment, two random variables, which are the percentage of thickness loss over time and the yield strength of the steel, have been considered. For each time points of the life cycle interval, the distributions of the ultimate flexural strength of the beam has been then obtained by repeated structural analysis. Finally, assuming a time-invariant bending moment, characterised by a normal distribution, a reliability index $\beta$ has been computed and then compared with the target levels defined in the Eurocode (2002).

The study revealed that, although the reduction of the ultimate flexural strength of the beam may not appear extreme, the probability of failure sharply increase with time.

The proposed methodology shall be applied to quantify the corrosion allowances in the structural dimensioning of steel members that cannot be inspected and maintained during service life, according to a reliability based design approach.

In particular, the redundancy of the member shall be evaluated on the basis of the service life of the structure and of the likely reliability reduction evaluated as presented in the paper.

This study, gaining together the results of different studies carried out in the field of material deterioration, structural design and reliability based design, can be considered as a first attempt to evaluate, in a common framework, the time dependant performance of CFS, according to a quantitative approach. Of course, further developments are required for the application of the proposed approach to complex structures. Those may include the evaluation of other relevant likely failure modes at component level, the development of corrosion damage models considering the effect of the stress state and stress history of structural components, the extension of the developed application to whole structures, according to the system-based analysis approach. 


\section{References}

Albrecht, P.; Hall, T. T. 2003. Atmospheric corrosion resistance of structural steels, Journal of Materials in Civil Engineering 15(1): 2-24.

http://dx.doi.org/10.1061/(ASCE)08991561(2003)15:1(2)

ASTM A1003/A1003. Standard specification for steel sheet, carbon, metallic- and nonmetallic-coated for cold-formed framing members. American Society for Testing and Materials. West Conshohocken, PA, 2006. 7 p.

Biondini, F.; Bontempi, F.; Frangopol, D. M.; Malerba P. G. 2006. Probabilistic service life assessment and maintenance planning of concrete structures, Journal of Structural Engineering 132(5): 810-825. http://dx.doi.org/10.1061/(ASCE)07339445(2006)132:5(810)

Biondini, F.; Frangopol, D. M. (Eds.). 2008. Life-cycle civil engineering. New York: CRC Press. 990 p.

Biondini, F.; Frangopol, D. M. 2009. Lifetime reliability-based optimization of reinforced concrete cross-sections under corrosion, Structural Safety 31(6): 483-489. http://dx.doi.org/10.1016/j.strusafe.2009.06.008

Cascini, L.; D'Aniello, M.; Portioli, F.; Landolfo, R. 2012. Service life assessment of steel riveted railway bridges: a case study, in Proc. of the Sixth International Conference on Bridge Maintenance, Safety and Management (IABMAS-2012), 8-12 July, 2012, Stresa, Italy.

Cascini, L.; Landolfo, R.; Portioli, F. 2008. An integrated approach to durability design of steel structures against atmospheric corrosion, Key Engineering Materials 385(387): 657-660.

Cissel, J. H.; Quinsey, W. E. 1942. Durability of lightweight steel construction, part II - a study of the service records of lightweight steel construction. Engineering Research Bulletin 30, Ann Arbor: University of Michigan.

Czarnecki, A. A.; Nowak, A. S. 2008. Time variant reliability profiles for steel girder bridges, Structural Safety 30(1): 49-64. http://dx.doi.org/10.1016/j.strusafe.2006.05.002

EN 1090-1. Execution of steel structures and aluminium structures - Part 1: Requirements for conformity assessment of structural components. European committee for standardization. Brussels, 2009. $42 \mathrm{p}$.

EN 1090-2. Execution of steel structures and aluminium structures - Part 2: Technical requirements for steel structures. European committee for standardization. Brussels, 2008. 203 p.

Eurocode 3: Design of steel structures - Part 1-1: General rules and rules for buildings. European committee for standardization. Brussels, 2005.91 p.

Eurocode: Basis of structural design. European committee for standardization. Brussels, 2002. 89 p.

Fisher, J. W.; Kaufmann, E. J.; Pense, A. W. 1998. Effect of corrosion on crack development and fatigue life, Journal of the Transportation Research Board 1624: 110-117.

Frangopol, D. M. 2011. Life-cycle performance, management, and optimisation of structural systems under uncertainty: accomplishments and challenges, Structure and Infrastructure Engineering 7(6): 389-413. http://dx.doi.org/10.1080/15732471003594427

ISO 12944-1. Paints and varnishes - Corrosion protection of steel structures by protective paint systems - Part 1: General introduction. International Organization for Standardization. Genève, 1998. 6 p.
ISO 13823. General principles on the design of structures for durability. International Organization for Standardization. Genève, 2008. 39 p.

ISO 14713. Zinc coatings - Guidelines and recommendations for the protection against corrosion of iron and steel in structures - Part 1: General principles of design and corrosion resistance. International Organization for Standardization. Genève, 2009. $17 \mathrm{p}$.

ISO 18072-1. General requirements for limit state assessment of ship structures. International Organization for Standardization. Genève, 2007.

ISO 2394. General principles on reliability for structures International Organization for Standardization. Genève, 1998. $73 \mathrm{p}$.

ISO 9223. Corrosion of metals and alloys. corrosivity of atmospheres. classification. International Organization for Standardization. Genève 1992. 13 p.

ISO 9224. Corrosion of metals and alloys. corrosivity of atmospheres. Guiding values for the corrosivity categories. International Organization for Standardization. Genève 1992. $3 \mathrm{p}$.

Ivanov, L. D. 2009. Challenges and possible solutions of the time-variant reliability of ship's hull girder, Ships and Offshore Structures 4(3): 215-228.

Kaiser, J. R.; Nowak, A. 1989. Capacity loss due to corrosion in steel-girder bridges, Journal of Structural Engineering 115(6): 1525-1537.

http://dx.doi.org/10.1061/(ASCE)07339445(1989)115:6(1525)

Klinesmith, D. E.; McCuen, R.; Albrecht, P. 2007. Effect of environmental condition on corrosion rate, Journal of Materials in Civil Engineering 19(2): 121-129.

http://dx.doi.org/10.1061/(ASCE)08991561(2007)19:2(121)

Knotkova, D.; Dean, S. W.; Yuichi, I.; Tidblad, J. 2010. Future revision of classification of atmospheric corrosivity according to ISO 9223-9226, in Proc. of the $15^{\text {th }}$ Nordic Corrosion Congress, Stockholm, Sweden, 2010.

Kulicki, J.; Prucz, Z.; Sorgenfrei, D.; Mertz, D.; Young, W. 1990. Guidelines for evaluating corrosion effects in existing steel bridges. NCHRP Report Number 333. Washington (DC): Transportation Research Board.

Landolfo, R.; Cascini, L.; Portioli, F. 2010. Modeling of metal structure corrosion damage: a state of the art report, Sustainability 2(7): 2163-2175.

Landolfo, R.; Cascini, L.; Portioli, F. 2011 Sustainability of steel structures: towards an integrated approach to lifetime engineering design, Frontiers of Architecture and Civil Engineering in China 5(3): 304-314.

Larson, J.; Usami, P. E. 2007. Technical note D200 corrosion protection for cold-formed steel framing in coastal areas. Washington: Cold-Formed Steel Engineers Institute. 6 p.

Li, Z.; Schafer, B. W. 2010. Buckling analysis of cold-formed steel members with general boundary conditions using CUFSM: conventional and constrained finite strip methods, in Proc. of the $20^{\text {th }}$ International Specialty Conference on Cold-Formed Steel Structures, Saint Louis, Missouri, 2010.

Melchers, R. E. 1999. Structural reliability analysis and prediction. $2^{\text {nd }}$ ed. Chichester: John Wiley \& Sons. 437 p.

Melchers, R. E.; Paik, J. K. 2010. Effect of flexure on rusting of ship's steel plating, Ships and Offshore Structures 5(1): 25-31.

Mirambell, E. 2004. Structural damage in steel construction: regulatory aspects, Progress in Structural Engineering and Materials 6(1): 56-68. 
NACE International Glossary of Corrosion-Related Terms [online]. 2002. Houston: NACE International [cited 27 January 2009]. Available from Internet: $\mathrm{http}: / /$ events.nace.org/pubsonline/free/glossary.pdf

North American Specification. Appendix 1: Design of coldformed steel structural members using the direct strength method. Supplement to the North American Specification for the Design of Cold-Formed Steel Structures. American Iron and Steel Institute, Washington, DC, 2004.

Okasha, N. M.; Frangopol, D. M. 2010. Advanced modeling for efficient computation of life-cycle performance prediction and service-life estimation of bridges, Journal of Computing in Civil Engineering 24(6): 548-556. http://dx.doi.org/10.1061/(ASCE)CP.1943-5487.0000060

Olsson, A.; Sandberg, G.; Dahlblom, O. 2003. On Latin hypercube sampling for structural reliability analysis, Structural Safety 25(1): 47-68. http://dx.doi.org/10.1016/S0167-4730(02)00039-5

Popo-Ola, S. O.; Biddle, A. R.; Lawson, R. M. 2000. Durability of light steel framing in residential buildings. SCI Publication P262. Ascot: The Steel Construction Institute.

Probabilistic model code. Part 1: Basis of design. [online]. 2000. Joint committee on structural safety [cited 23 December 2011] Available from Internet:

http://www.jcss.byg.dtu.dk/Publications/Probabilistic_Mo del_Code.aspx

Prucz, Z.; Kulicki, J. M. 1998. Accounting for effects of corrosion section loss in steel bridges, Journal of the Transportation Research Board 1624: 101-109.

Reid, S. G. 2009. Calculation and interpretation of realistic reliability estimates, Ships and Offshore Structures 4(3): 197-205.

Roberdge, P. R. 2000. Handbook of corrosion engineering. New York: McGraw-Hill. 1128 p.

Rourke, D.; Larson, J.; Allen, D.; Crawford, M.; Ken deSouza, K.; Elhajj, N.; Rolih, G.; Usami, A.; Wellinghof, J. 2007. Technical note D001-07 durability of cold-formed steel framing members. Washington: Cold-Formed Steel Engineers Institute. $8 \mathrm{p}$.

Sarveswaran, V.; Smith, J. W.; Blockley, D. I. 1998. Reliability of corrosion damaged steel structures using interval prob- ability, Structural Safety 20(3): 237-255.

http://dx.doi.org/10.1016/S0167-4730(98)00009-5

Saydam, D.; Frangopol, D. M. 2011. Time-dependent performance indicators of damaged bridge superstructures, Engineering Structures 33(9): 2458-2471.

http://dx.doi.org/10.1016/j.engstruct.2011.04.019

Schafer, B. W. 2006. Review: the direct strength method of cold-formed steel member design, in Proc. of Stability and Ductility of Steel Structures. Camotim, D., et al. (Eds.). 6-8 September, 2006, Lisbon, Portugal.

Schafer, B. W.; Ádány, S. 2006. Buckling analysis of coldformed steel members using CUFSM: conventional and constrained finite strip methods, in Proc. of Eighteenth International Specialty Conference on Cold-Formed Steel Structures, October, 2006, Orlando, FL.

Sharifi, Y.; Paik, J. K. 2011. Ultimate strength reliability analysis of corroded steel-box girder bridges, Thin-Walled Structures 49(1): 157-166.

http://dx.doi.org/10.1016/j.tws.2010.09.001

Steel framing alliance [online]. 2004. Corrosion of galvanized fasteners used in cold-formed steel framing: research report. RP04-4 Revision 2006 [cited 23 December 2011]. Available from Internet:

$\mathrm{http}: / /$ store.steelframingalliancestore.com/coofgafausin $1 . \mathrm{h}$ tml

UNI EN 12500. Protection of metallic materials against corrosion - Corrosion likelihood in atmospheric environment Classification, determination and estimation of corrosivity of atmospheric environments. Ente Nazionale Italiano di Unificazione. 2002, Milano. 18 p.

van de Lindt, J. W.; Ahlborn, T. M. 2005. Development of steel beam end deterioration guidelines [online], [cited 15 September 2011]. MDOT Research Report RC-1454. Available from Internet:

http://www.engr.colostate.edu/ jwv/pdf files/MDOT\%20 Steel\%20Beam\%20End\%20Deterioration\%20Report.pdf

Vernon, W. J. 1935. A laboratory study of the atmospheric corrosion of metals. Part I - The corrosion of copper in certain synthetic atmospheres, with particular reference to the influence of sulphur dioxide in air of various relative humidities, Transactions of Faraday Society 27: 255-277.

Lucrezia CASCINI. She is a PhD, Engineer, has been serving as Postdoctoral Research Fellow in Structural Engineering at the University of Naples "Federico II" since 2010. She is a member of the "International Association for Life-Cycle Civil Engineering (IALCCE)" since 2009. She is the author of several scientific papers mainly concerning metal constructions and durability design. She was involved in the activities of Working Group 3 of the COST Action C25 on "Sustainability of Constructions: Integrated Approach to Life-time Structural Engineering" whose goals were mainly related to the design of structures for durability, and the life cycle performance design.

Francesco PORTIOLI. He is a PhD, Engineer, an Assistant Professor in Structural Engineering at the University of Naples "Federico II" since 2006. He has been involved in several international and national research projects. He was a Member of Work Package 8 of the COST Action C25 on "Sustainability of Constructions: Integrated Approach to Lifetime Structural Engineering". He was a Member of Work Package 8 on Numerical analysis, in the research project PROHITECH, Earthquake Protection of Historical Buildings by Reversible Mixed Technologies, EU FP6. He is the author of more than 60 scientific papers mainly concerning metal and masonry structures.

Raffaele LANDOLFO. He is a PhD, Engineer, a Full Professor of Structural Engineering at the University of Naples "Federico II" since 2003. He is currently the Head of the Department of Structures for Engineering and Architecture at the University of Naples. He has been serving as a Chairman of the Working Group 3 within the European project COST Action C25 "Sustainability of Constructions: Integrated approach to Life-time Structural Engineering". Since September 2007, he is chairing the ECCS Technical Committee n.13 on Seismic Design and he has also been serving as a member of both the Seismic Committee within "Fondazione Promozione Acciaio" (since 2005) and the Steering Committee of the National Council of Steel Technicians (since 2006). He is a designer of several steel structures including the space structure of Malpensa airport in Milan (in cooperation) and the steel structures of the extension of the Architectural Faculty in Pescara. His research activity involves the participation in several national and international research projects. He published a book and more than 200 scientific papers, mainly on national and international journals, on topics related to metal structures and seismic design. 